\title{
Anhidrotic ectodermal dysplasia with lacrimal anomalies
}

\author{
G. M. LIAKOS \\ From the Southampton Eye Hospital
}

SUMMARY Ectodermal dysplasia and its related disorders may present with ocular symptoms due to involvement of the ectodermal components of the eye. This paper reports a case of congenital anhidrotic ectodermal dysplasia presenting to the ophthalmologist with epiphora due to lacrimal atresia. The embryonic origin of the lacrimal system suggests that lacrimal anomalies in association with ectodermal disorders are commoner than reports indicate. Their management consists in accurate evaluation of the anomaly followed by surgery.

Various forms of ectodermal dysplasia have been reported. They mainly affect the skin and its appendages, but occasionally the ocular structures are involved as well. The commonest ocular complications reported consist mainly of corneal, lenticular, and retinal changes. This paper reports a case of anhidrotic ectodermal dysplasia associated with lacrimal anomalies.

\section{Case report}

A 12-year-old girl presented to the casualty department of the Southampton Eye Hospital complaining of epiphora, which was bilateral and present since birth. The patient had already been seen by an ophthalmologist, who diagnosed punctal atresia. Both lower lacrimal papillae were incised, which had been followed by probing. In spite of that procedure, epiphora remained constant.

General examination showed the unmistakable stigmata of anhidrotic ectodermal dysplasia. These included scarcity of hair growth, particularly evident in the scalp, where the hair was scanty, brittle, and fair, with a small patch of baldness over the vertex, and receding hair line (Fig. 1). Sweat and sebaceous glands were entirely absent so that the skin was xerotic and hyperkeratotic, with hyperpigmented creases (Fig. 2). The nails were abnormal (Fig. 3), and the teeth were either absent or deformed. Her general physical development was poor and the height below average for her age.

Ophthalmic examination showed very sparse eyebrows and eyelashes, the lateral two-thirds being

Address for reprints: Dr G. M. Liakos, Southampton Eye Hospital, 2 Wilton Avenue, Southampton, Hants SO9 4XW

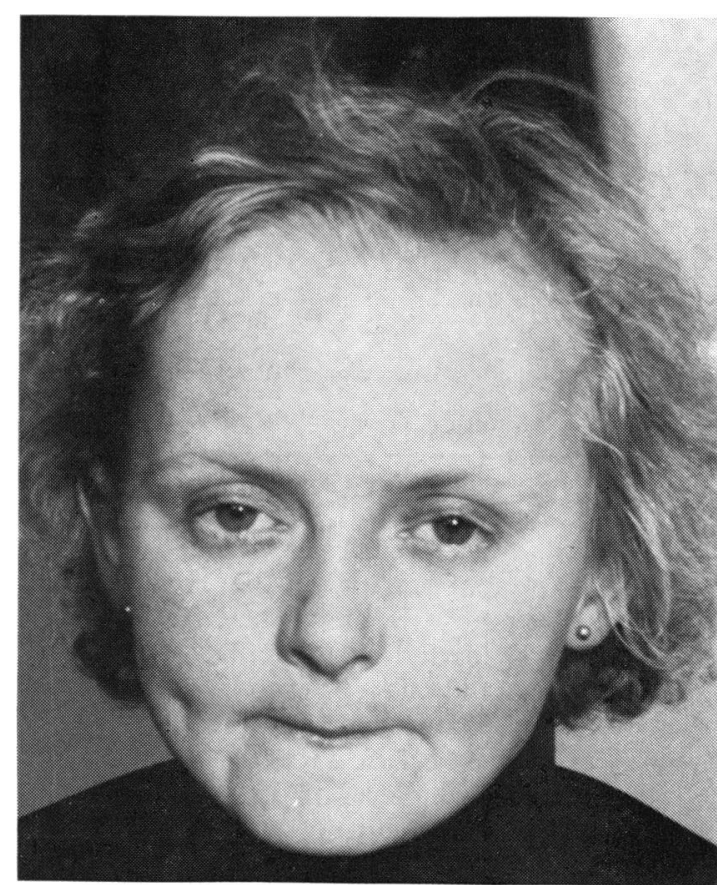

Fig. 1 Scanty, brittle hair, frontal baldness, sparse eyebrows and eyelashes, hypodontia

almost absent. Gross epiphora was present, leading to skin excoriation. There was atresia of the upper puncta, while the lower ones were incised. Visual acuity was recorded as $6 / 6$ in each eye, and the intraocular pressure was normal. Examination of the corneae, lenses, and retinae failed to reveal any abnormalities. 
Fig. 2 Hyperkeratotic skin with hyperpigmented creases
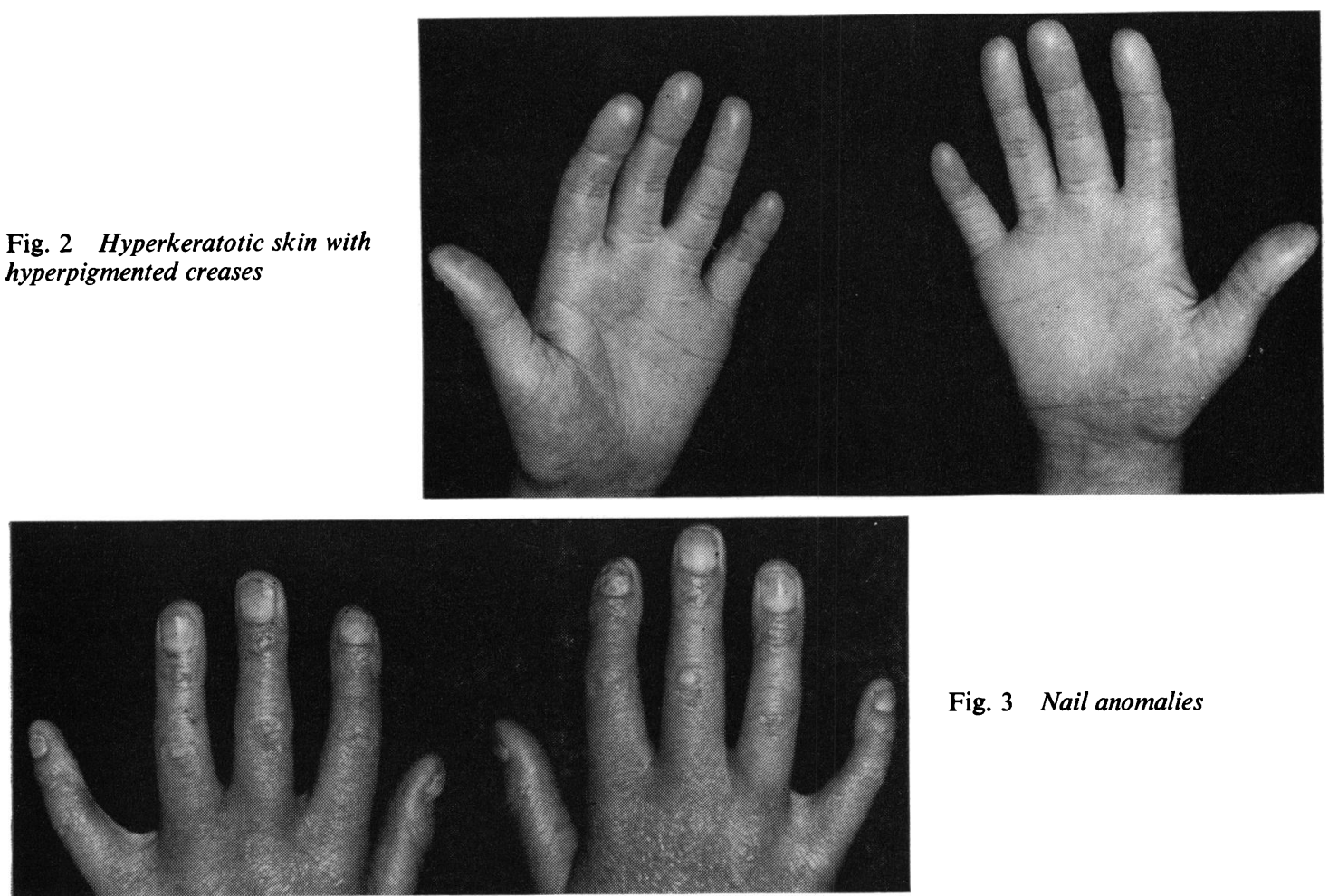

Fig. 3 Nail anomalies

Contrast dacryocystography showed the presence of proximal canalicular atresia, the dye failing to enter the lacrimal sac. Surgical exploration followed, which confirmed total absence of upper canaliculus, proximal obstruction of lower canaliculus, and normal sac and nasolacrimal duct. In view of these findings, a dacryocystorhinostomy was performed with canalicular intubation. Two months later the result was satisfactory.

\section{Discussion}

Since Wedderhorn (1838) first described anhidrotic ectodermal dysplasia in a Hindu family many similar reports have appeared, mainly in the paediatric, dermatological, and dental literature. Several other hereditary syndromes (Rothmund's, Werner's, progeria, etc.) are closely related to ectodermal dysplasia, all resulting from a maldevelopment of the embryonic ectoderm.

Ocular involvement as one would expect is mainly centred round the ectodermal tissues, although occasionally mesodermal parts of the eye are affected as well. Although Thannhauser (1946) stated that 'none of the numerous cases of ectodermal dysplasia reported in the literature exhibited either cataracts in infancy or in later life', in the following years several authors described congenital cataracts as the commonest ocular complication of ectodermal dysplasia (Gregory, 1955; Mankopf and Hanney, 1957; Marshall, 1958). Other complications include strabismus (Marshall, 1958), corneal anomalies (Kline, 1959; Jung, 1966), Reiger's dysgenesis (Gassler and Berthold, 1960), fibrous tissue in the anterior part of the vitreous, and chorioretinal atrophy (Gregory, 1955).

It is surprising that lacrimal anomalies as a complication of ectodermal dysplasia have only been reported twice, by Mankopf and Hanney (1957) and Beckerman (1973). Embryologically the lacrimal system derives from the surface ectoderm by an original inclusion of a group of cells which forms the sac and subsequently proliferates and canalises to form the canaliculi and nasolacrimal duct. One therefore would expect lacrimal anomalies to be a common complication of ectodermal dysplasia and other related syndromes, but these could easily be missed if such a patient is not examined by an ophthalmologist, who is more aware and better equipped to recognise them. Beckerman also suggests that associated lacrimal gland hypoplasia may reduce the flow of tears and conceal lacrimal drainage problems. In addition, when anomalies are restricted in the upper canaliculus, the functional 
capacity of the lacrimal draining system is maintained and symptoms are absent.

Thus it is likely that lacrimal complications are commoner than reports suggest but often pass unnoticed as a result of the above-mentioned factors. Their recognition frorn an ophthalmologist's point of view is important for two reasons: firstly, in the few cases that present first to the ophthalmologist an appreciation of the generalised disorder is necessary to ensure that the patient is referred for further investigation and treatment. Secondly, the treatment of these anomalies follows the pattern of acquired obstructions rather than the customary probing which is the treatment of choice for persistent congenital epiphora. Repeated probings can only prove harmful, and instead dacryocystography should be performed, which will reveal the exact nature of the anomaly. Further management will almost certainly involve surgery, in the form of dacryocystorhinostomy, with or without intubation, depending on the site of the obstruction.

I thank Mr C. B. Walker for allowing me to study his case. I am also grateful to Mr F. Sims for the illustrations and to Mrs J. M. Shapter for secretarial assistance.

\section{References}

Beckerman, B. L. (1973). Lacrimal anomalies in anhidrotic ectodermal dysplasia. American Journal of Ophthalmology, 75, 728-730.

Gassler, H., and Berthold, H. (1960). A contribution to ectodermal dysplasia from the ophthalmological point of view. Klinische Monatsblätter für Augenheilkunde, 136, $52-65$.

Gregory, I. D. R. (1955). Congenital ectodermal dysplasia. British Journal of Ophthalmology, 39, 44-47.

Jung, E. C. (1966). Anhidrotic ectodermal dysplasia with corneal dystrophy. Schweizerische medizinische Wochenschrift, 96, 1477-1482.

Kline, A. H., Sidbury, J. B., and Richter, C. P. (1959). The occurrence of ectodermal dysplasia and corneal dysplasia in one family. Journal of Pediatrics, 55, 355-366.

Mankopf, H., and Hanney, F. (1957). Zum Erscheinungsbild der Kongenitalen extodermalen Dysplasien. Albrecht von Graefes Archiv für klinische und experimentelle Ophthalmologie, 159, 643-661.

Marshall, D. (1958). Ectodermal dysplasia: report of kindred with ocular abnormalities and hearing defect. American Journal of Ophthalmology, 45, 143-156.

Thannhauser, S. J. (1946). Differential diagnosis of ectodermal dysplasia and of Rothmund's syndrome. Journal of the American Medical Association, 130, 238.

Wedderhorn, W. (1893). Quoted in Darwin, C. R. Animals and Plants under Domestication, 2nd edn., vol. 2, p. 319. Murray: London. 